\title{
Application of faecal calprotectin as marker of gastrointestinal tract disorders
}

\author{
Magdalena Trzepizur, Ewa Toporowska-Kowalska \\ Department of Allergology, Gastroenterology and Child Nutrition, Medical University in Lodz, Poland
}

\section{ABSTRACT}

Calprotectin refers to the S100A8 and S100A9 protein complex, also known as the 27E10 antigen, L1L and $\mathrm{L} 1 \mathrm{H}, \mathrm{MRP}-8 / 14$, or calgranulin A/B protein. Faecal calprotectin (FC) is a marker of intestinal inflammation and neutrophil infiltration. This article aimed to review the methods of FC measurement and the importance of the test in the diagnostic workup of children with different disorders of the GI tract, including GI involvement in COVID-19. We found that it is helpful in differentiating between functional and organic disorders and monitoring patients with inflammatory bowel diseases. Different cut-off values are applied in children depending on the patient's age; hence, variability of the parameter for a given patient should be analysed.

KEY WORDS:

COVID-19, inflammatory bowel disease, faecal calprotectin, functional gastrointestinal disorders.

\section{INTRODUCTION}

Calprotectin is one of the most commonly used names of the S100A8 and S100A9 protein complex, also referred to as the 27E10 antigen, L1L and L1H, MRP-8/14, or calgranulin $\mathrm{A} / \mathrm{B}$ protein [1]. It is a calcium- and zinc-binding intracellular protein of the $\mathrm{S} 100$ protein group, consisting of two heavy $14 \mathrm{kDa}$ chains and one light $8 \mathrm{kDa}$ chain. It is mainly produced by neutrophils (constituting $30-60 \%$ of cytoplasmic proteins) and, to a lesser extent, by monocytes and activated macrophages [2]. Further, immunohistochemical studies have demonstrated the presence of calprotectin on the membranes of the non-horny squamous epithelia and renal tubules [1].

The S100A8/S100A9 protein plays a regulatory role in inflammatory reactions as an antibacterial (bacteriostatic) and antiproliferative agent. Activated neutrophils release a considerable amount of calprotectin, increasing its concentration in body fluids (serum, cerebrospinal fluid, synovial fluid, urine, and saliva) and faeces, which makes the protein a good marker for diseases associated with gastrointestinal (GI) tract inflammation [2].
Calprotectin concentration in faeces is proportional to the number of neutrophils migrating to the GI tract mucosa. The clinical applicability of faecal calprotectin (FC) is best explored in inflammatory bowel disease (IBD). It has been proven that protein concentration rises in a flare-up of the disease, which makes FC a globally accepted diagnostic tool for diagnosing and monitoring IBD in various clinical scenarios [3]. The increased concentration of FC has also been intensively investigated in many other GI and extra GI conditions, including necrotising enterocolitis, coeliac disease, cystic fibrosis, food allergy, colorectal cancers, inflammation of the GI tract mucosa associated with non-steroidal anti-inflammatory drugs (NSAIDs) use, infections, acute pancreatitis, liver cirrhosis, and after significant physical exertion $[1,2,4,5]$. During this era of the COVID-19 pandemic, increasing attention has been paid to the potential role of FC as a marker of GI tract involvement in patients with COVID-19. This article aimed to review the methods of FC measurement and the importance of the test in the diagnostic workup of children with different disorders of the GI tract.

\section{ADDRESS FOR CORRESPONDENCE:}

Magdalena Trzepizur, Department of Allergology, Gastroenterology and Child Nutrition, Medical University in Lodz, Poland, e-mail: madzia.trzepi@gmail.com 


\section{CALPROTECTIN REFERENCE VALUES IN HEALTHY CHILDREN}

There is a high degree of variability in FC concentrations between individuals [3]. Most publications assume a cut-off point of $50 \mu \mathrm{g} / \mathrm{g}$ in faeces for adults and children $>4$ years of age, while there are no commonly accepted values for children below that age threshold [6]. Figure 1 presents cut-off values depending on age in the paediatric population [7-12]. Faecal calprotectin concentration can be affected by extraintestinal bleeding, such as epistaxis and menstrual bleeding [6]. An amount of $\geq 100 \mathrm{ml}$ of blood loss/day may increase FC concentration, leading to false positive results [6]. The FC concentration may also be affected by bowel preparation; hence FC measurement should not be performed for several days after bowel cleansing and colonoscopy [3].

A slight influence of diet and physical activity has also been reported [6]. Furthermore, the concentration of FC in diaper-collected samples may be elevated because of water absorption [3].

\section{COLLECTION, STORAGE OF STOOL SAMPLES, AND FAECAL CALPROTECTIN DETERMINATION METHODS}

Calprotectin concentrations may be measured using immunochromatography (Quick Check Gernon [RAL, Barcelona, Spain], CalDetect 50/200 [Preventis GmbH Bensheim, Germany], Calfast [Eurospital, Trieste, Italy]), immunoenzymatic (calprotectin ELISA [Buhlmann, Schonenbuch, Switzerland], quantitative faecal calprotectin [DIASource, OttigniesLouvain-la-Neuve, Belgium], Calpro EasyExtract ${ }^{\mathrm{Tm}}$ and Calprolab ${ }^{\mathrm{Tm}}$ HRP [both by Calpro AS, Lysaker, Norway]), fluoroimmunoenzymatic (Elia Calprotectin [Thermo Fisher, Uppsala, Sweden]), turbidimetric (Calprotectin turbo) tests, and chemiluminescent immunoassay (LIAISON ${ }^{\circledR}$ Calprotectin [DIASorin, Saluggia, Italy]) [13].

\section{COLLECTION AND STORAGE OF FAECAL SAMPLES}

A small sample of faeces $(5 \mathrm{~g})$ is considered sufficient to determine the protein concentration. The ability of cal- protectin to bind to calcium makes it resistant to proteolytic enzyme action and ensures stability. Generally, based on published data, FC concentration appears to be stable at room temperature for 4-7 days, depending on the manufacturer's specifications [14]. For example, for LIAISON $^{\circledR}$ Calprotectin (DIASorin, Saluggia, Italy), Calprotectin ELISA (Buhlmann, Schonenbuch, Switzerland), and Calpro EasyExtract ${ }^{\mathrm{Tm}}$ (Calpro AS, Lysaker, Norway), the FC concentration is expected to be stable for 4 hours, up to 3 days, and up to 5 days, respectively [13].

According to the recommendations of most manufacturers, a sample of faeces with a buffer can also be stored in a refrigerator at a temperature $2-8^{\circ} \mathrm{C}$ for $2-7$ days. An exception is the Elia Calprotectin test (Thermo Fisher, Uppsala, Sweden), for which sample storage at refrigerator temperature is not recommended because of the possibility of decreasing the FC concentration in the sample [13].

At a temperature of $-20^{\circ} \mathrm{C}$, stool samples with a buffer can be stored for periods from several months (Calfast [Eurospital, Trieste, Italy], Calpro EasyExtract ${ }^{\mathrm{Tm}}$ [Calpro AS, Lysaker, Norway], Elia Calprotectin [Thermo Fisher, Uppsala, Sweden]) to over 24 months (Calprotectin turbo [Buhlmann, Schonenbuch, Switzerland], Calprolab $^{\text {ts }}$ HRP [Calpro AS, Lysaker, Norway]), depending on the test type, although this is not recommended for the LIAISON ${ }^{\circledR}$ Calprotectin test.

The sensitivity and specificity of various tests measuring FC concentrations differ depending on the methodology they are based on.

Acevedo et al. [13] compared the new-generation ELISA methods, Calprolab Calprotectin ELISA (Calpro AS Lysaker, Norway) and ELISA Calprotectin fluoroenzymoimmunoassay (Thermo Fisher, Uppsala, Sweden), and tested the stability of FC in faecal extracts stored in the Calpro AS extraction buffer at room temperature in patients with various conditions (IBD, bacterial colitis, intestinal polyps, diverticulitis, haemorrhoids, non-specific colitis, lactose intolerance, coeliac disease, a1-antitrypsin deficiency, Helicobacter pylori gastritis, gastroesophageal reflux, Giardia lamblia infection, functional abdominal pain, NSAID-induced enteropathy, and low-dose acetyl salicylic acid [ASA] therapy). The highest sensitivity for IBD diagnosis was found in the Thermo Fisher method

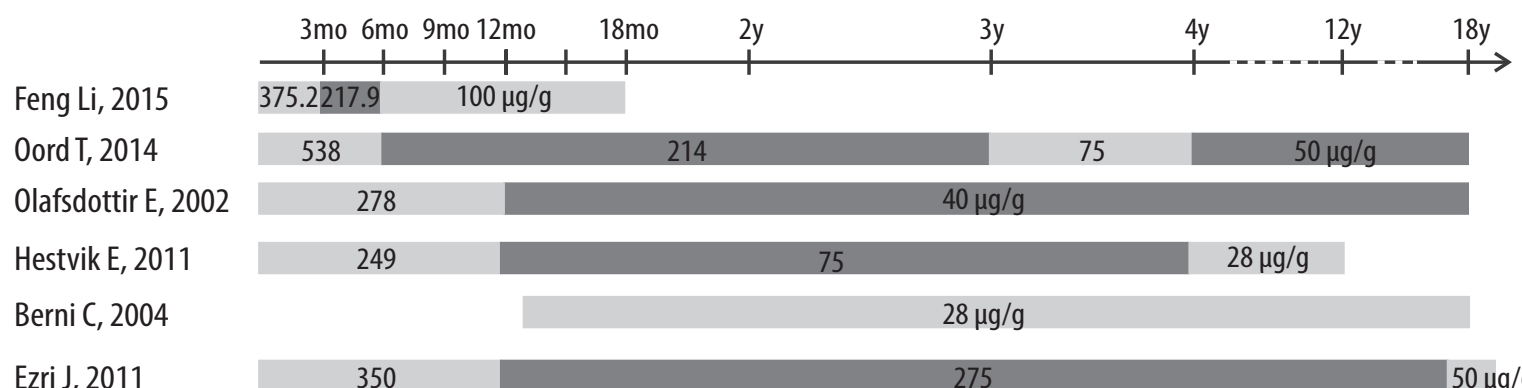

FIGURE 1. Normal level of faecal calprotectin depending of the age of children 


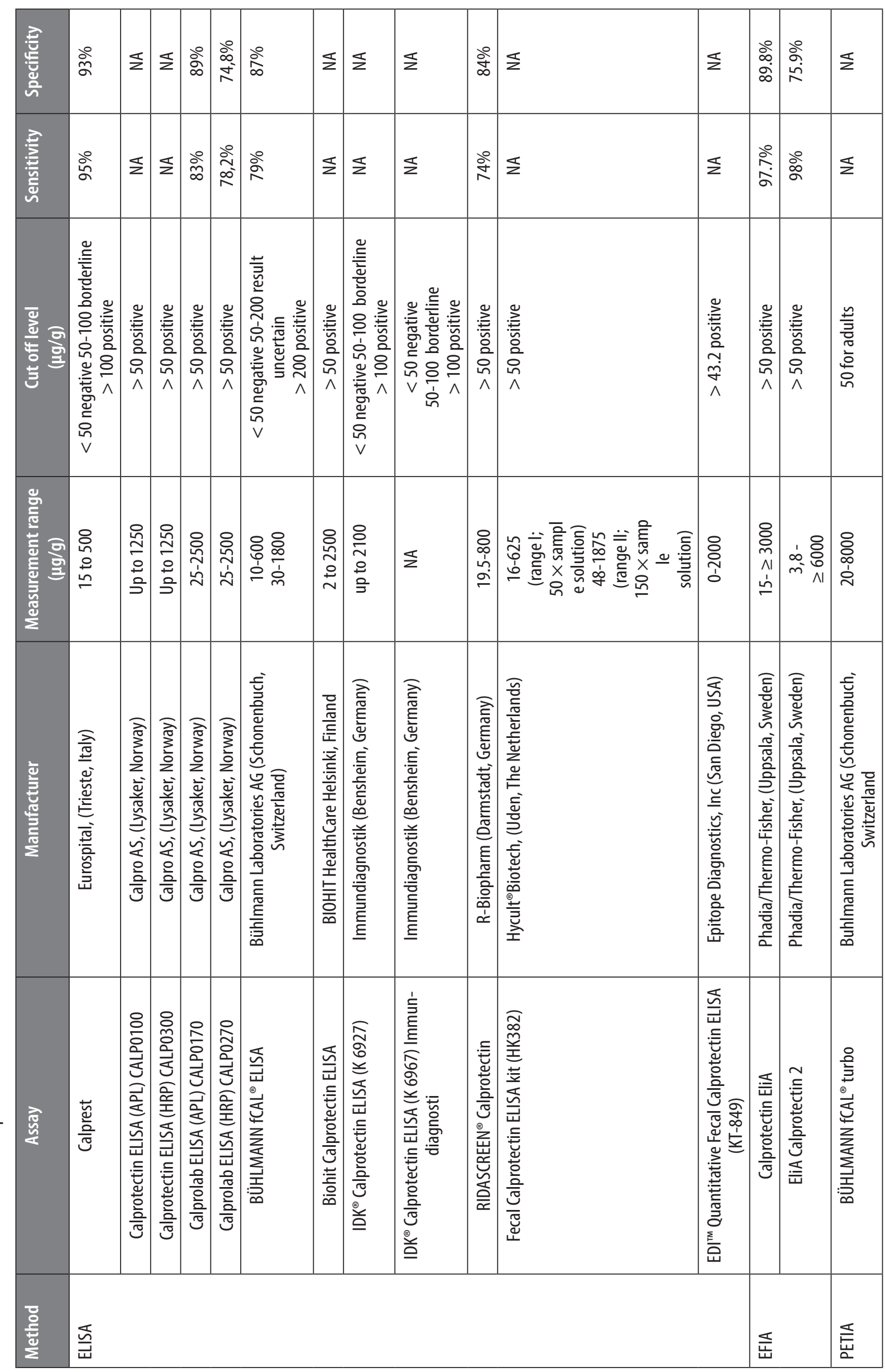




\begin{tabular}{|c|c|c|c|c|c|c|c|c|c|c|c|c|c|}
\hline 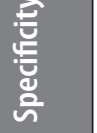 & $\begin{array}{l}\text { ¿ें } \\
\text { ळे }\end{array}$ & ڤે̀ & 乏 & & 高 & ळે̀̄ & ळें & ळ్ర & $\Sigma$ & ふें & $\Sigma$ & $\begin{array}{l}\text { ò } \\
\wedge\end{array}$ & $\begin{array}{l}\text { o̊ } \\
\text { ه̊ }\end{array}$ \\
\hline 竞 & $\begin{array}{l}\stackrel{\circ}{9} \\
\stackrel{\infty}{\circ}\end{array}$ & ळે̀ & $\Sigma$ & & ळે & $\begin{array}{l}\text { शे } \\
\text { ^̀ }\end{array}$ & ஓे & ळे & $\Sigma$ & 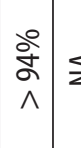 & $\Sigma$ ¿ & ஓ̊̊ & 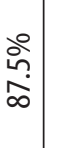 \\
\hline 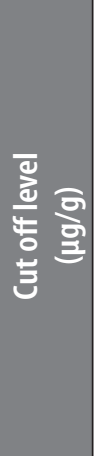 & 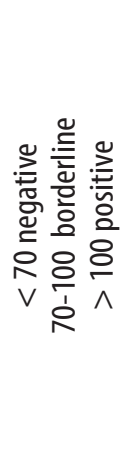 & 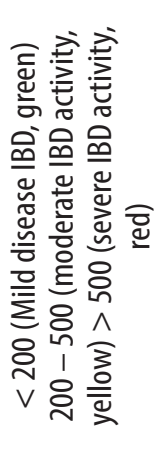 & 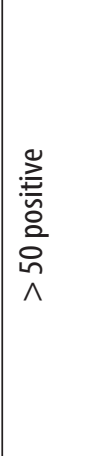 & 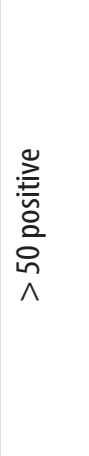 & 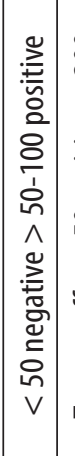 & 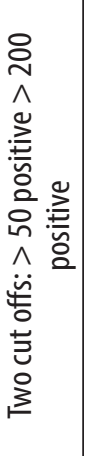 & 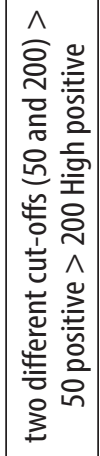 & 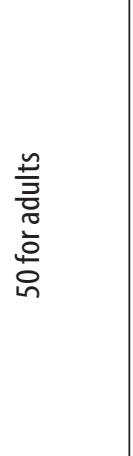 & 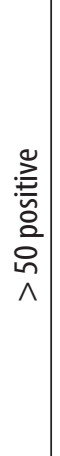 & 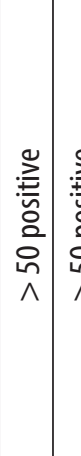 & 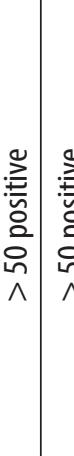 & 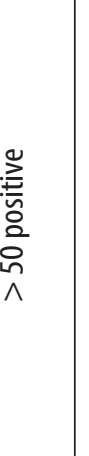 & 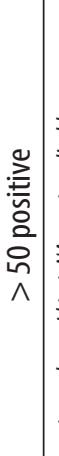 \\
\hline 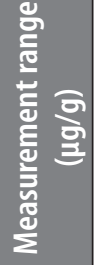 & $\begin{array}{l}8 \\
\text { ते } \\
\text { cे }\end{array}$ & 宮 & $\frac{8}{\frac{8}{1}}$ & 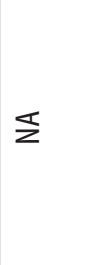 & 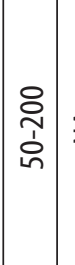 & $\Sigma$ & 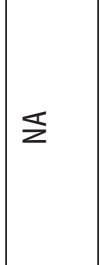 & 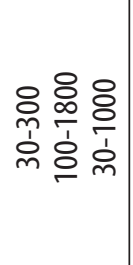 & $\mid \begin{array}{l}0 \\
0 \\
0 \\
0 \\
0 \\
3\end{array}$ & $\Sigma$ & $\Sigma \mid \begin{array}{l}c \\
z \\
c\end{array}$ & 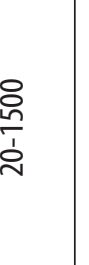 & $\begin{array}{l}8 \\
0 \\
0 \\
n \\
n\end{array}$ \\
\hline 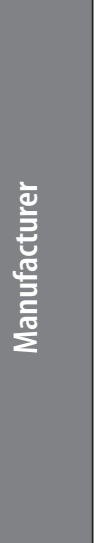 & 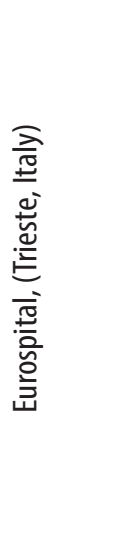 & 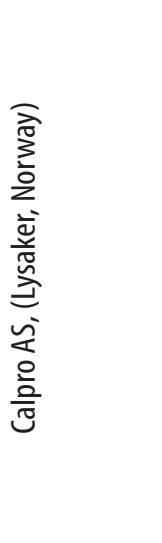 & 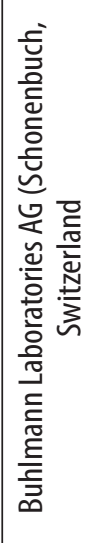 & 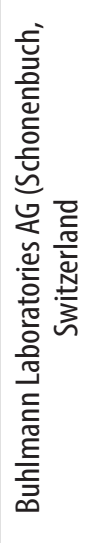 & 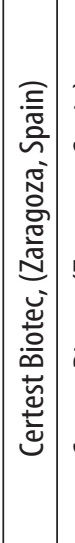 & 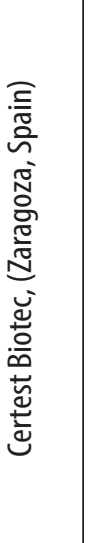 & 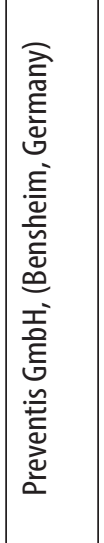 & 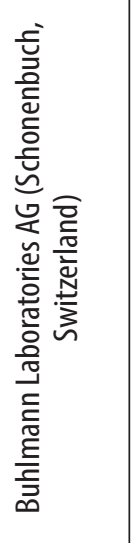 & 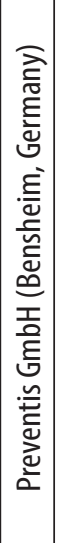 & 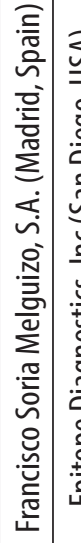 & 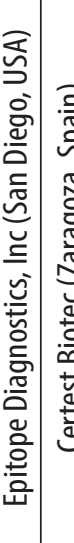 & 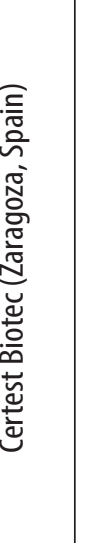 & 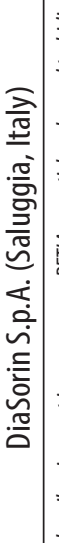 \\
\hline 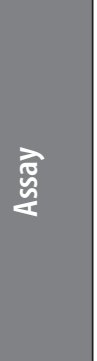 & 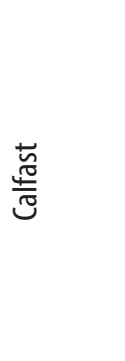 & 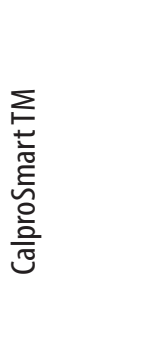 & 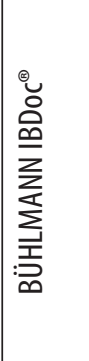 & 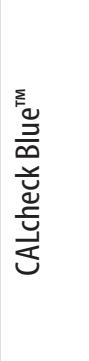 & 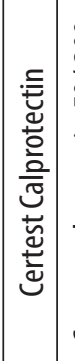 & 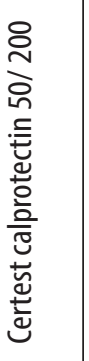 & 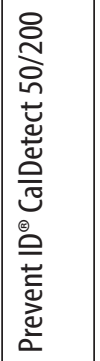 & 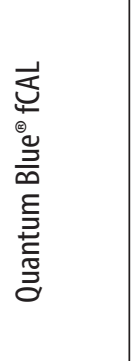 & 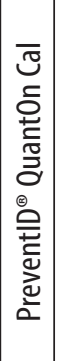 & 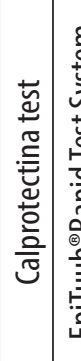 & 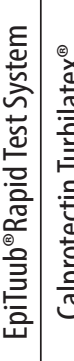 & 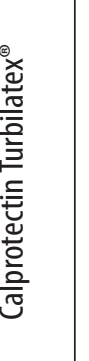 & 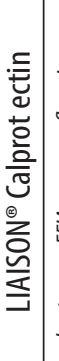 \\
\hline $\begin{array}{l}\text { c } \\
\text { ț } \\
\text { d }\end{array}$ & 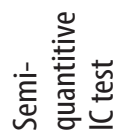 & & & & & & & 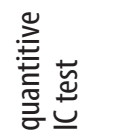 & & & & 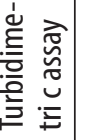 & \\
\hline
\end{tabular}


with a cut-off of $50 \mu \mathrm{g} / \mathrm{g}$ ( $81.8 \%$ vs. $72 \%$ in Calpro AS), whereas the highest specificity was seen in Calpro AS (83.2\% vs. $75.5 \%$ in Thermo Fisher; cut-off, $100 \mathrm{ug} / \mathrm{g}$ ). The positive predictive value for GI organic diseases (for both tests and cut-off points) was low (range 51.1-61.3\%), while the negative predictive value was high $(90 \%$ for $50 \mu \mathrm{g} / \mathrm{g}$ cut-off). Furthermore, the stability of the Calpro AS kit with a stool sample stored at room temperature was noted to be four days, which is an important practical point for the transport of samples [12].

According to the recent ESPGHAN guidelines (2021), faecal samples should not be kept before processing for FC concentration for more than 3 days at room temperature and for more than 7 days if refrigerated immediately after collection [3]. No specific diet was recommended before sample collection. Details of available tests for FC concentration measurement from different companies are described in Table 1 [3].

\section{HOME TESTING OF FAECAL CALPROTECTIN}

In Finland, Piekkala et al. [15] assessed the feasibility and accuracy of the IBDoc ${ }^{\oplus}$ test (Bühlmann Laboratories $\mathrm{AG}$ (Schonenbuch, Switzerland) designed for home/ office-based FC concentration measurement (range, $<30 \mu \mathrm{g} / \mathrm{g}->1000 \mu \mathrm{g} / \mathrm{g}$ ) in children with IBD. A detailed description of IBDoc (Bühlmann Laboratories AG (Schonenbuch, Switzerland)) is available at www.ibdoc. net. Patients were instructed to collect a stool sample using the sampling pin of the CALEX ${ }^{\circledast}$ valve and place it back into the tube through the upper funnel. After a 2-24-hour incubation period, the sample was placed on the test cassette. After 12 minutes, a photo of the test box was taken and sent to www.ibdoc.net, where the results were interpreted. Home-based IBDoc results were compared with the laboratory ELISA method (CALPRO ${ }^{\circ}$ Calprotectin ELISA Test ALP) and the home IBDoc ${ }^{\circledast}$ performed by laboratory diagnosticians.

As many as $61 \%$ parents negatively assessed the IBDoc method due to difficulties in smartphone application use and significant differences between results obtained by IBDoc $^{\oplus}$ and classic ELISA tests. Notably, more similar results of FC were obtained if both tests were conducted by laboratory diagnosticians (in $82.2 \%$ of comparable results, FC concentrations differed by a median of $32 \mu \mathrm{g} / \mathrm{g}$, $p<0.0001$ ). In a similar study, Heida et al. [16] demonstrated that FC concentrations in patients with IBD obtained using IBDoc ${ }^{\circledR}$ home kits were comparable with ELISA and Quantum Blue tests for concentrations $<500 \mu \mathrm{g} / \mathrm{g}$.

The limitations of home calprotectin kits were also confirmed by Haisma et al. [17], who compared the results of three home assessment tests (IBDoc, QuantonCal, and CalproSmart) with ELISAs established by the same producers (fCAL, IDK-calprotectin, and calprotectin-ALP). At FC concentrations $\leq 500 \mu \mathrm{g} / \mathrm{g}$, IBDoc,
QuantOnCal, and CalproSmart demonstrated 87\%, 82\%, and $76 \%$ concordance with associated ELISAs, respectively. At FC concentrations $>500 \mu \mathrm{g} / \mathrm{g}$, the concordance was only $37 \%, 19 \%$, and $37 \%$, respectively. Moreover, the study found that CalproSmart and QuantOn Cal applications had considerably more reading errors than the IBDoc application (at $5.8 \%$ and $4.8 \%$, respectively, compared with 1.9\%) [17]. Hence, patients with higher FC concentrations on home-based tests should be further tested using a quantitative method. Despite the limitations of home-based calprotectin kits, they enable the patient and physician to obtain quick results [15].

\section{FAECAL CALPROTECTIN LEVELS IN DIFFERENT GASTROINTESTINAL TRACT CONDITIONS}

\section{INFLAMMATORY BOWEL DISEASE}

Faecal calprotectin is a well-established bowel inflammation marker in IBD; it allows monitoring of the disease course and predicts IBD exacerbation [3, 18-23]. In Crohn's disease (CD), colonic involvement and increased levels of FC may suggest active disease in the small intestine [3]. However, in patients with isolated ileocaecal valve involvement (which is a rare presentation of $\mathrm{CD}$ ), the FC level is low [3].

Faecal calprotectin concentrations in IBD correlate with the degree of macroscopic (Mayo score) and microscopic findings of intestinal inflammation [18-23]. However, no correlation was observed between the FC concentration and location of inflammatory lesions in the digestive tract [24].

There is no universally accepted cut-off value for screening for IBD in children. Although the The European Society for Paediatric Gastroenterology Hepatology and Nutrition (ESPGHAN) study [3] cited the cutoff level as $212 \mu \mathrm{g} / \mathrm{g}$ with a sensitivity of 0.90 (95\% CI: $0.87-0.93$ ) and specificity of 0.87 (95\% CI: 0.81-0.88), which is based on a systematic review and meta-analysis by Henderson et al. [25], no specific FC value is included in the statements or recommendations referring to IBD screening.

According to Gisbert et al. [6], FC allows detection of IBD with $80 \%$ sensitivity and $76 \%$ specificity (ulcerative colitis [UC] with $72 \%$ sensitivity and $74 \%$ specificity; CD with $83 \%$ sensitivity and $85 \%$ specificity). A higher usefulness in detecting flare-ups was noted in patients with UC than in those with CD, and in patients with colitis in the course of CD than in patients with the terminal small intestine affected $[24,26]$. Walkiewicz et al. [27] found that in asymptomatic patients with CD and FC $>400 \mu \mathrm{g} / \mathrm{g}$, flare-up occurred in $89 \%$ of the patients. Van Rheenen [28] observed that the risk of disease progression and a flare-up in adolescents with IBD was 53\% and $12 \%$ when FC concentration was $<500 \mu \mathrm{g} / \mathrm{g}$ and $>500 \mu \mathrm{g} / \mathrm{g}$, respectively. 
In patients with IBD, FC should be measured at least 6-monthly during follow-up and in remission, unless the clinical course suggests relapse. ESPGHAN proposed consideration of endoscopy in children with clinical remission of IBD and FC $>300 \mu \mathrm{g} / \mathrm{g}$.

ESPGHAN also proposed that FC should be used in the follow-up of paediatric IBD patients after intestinal surgery to detect early asymptomatic exacerbation requiring evaluation [3]. In patients with UC after colectomy, FC may be used as a screening tool for pouchitis (the level $>300 \mu \mathrm{g} / \mathrm{g}$ may suggest it, but lower levels do not preclude it) and inflammation at the anastomosis site.

\section{FAECAL CALPROTECTIN IN NON-INFLAMMATORY BOWEL DISEASE GASTROINTESTINAL DISORDERS}

\section{Necrotising enterocolitis}

Necrotising enterocolitis involves severe multifactorial damage to the intestines which arises from ischaemic, inflammatory, and necrotising lesions. It occurs in approximately $0.3-2.4 \%$ of neonates, but the incidence rises to $10-15 \%$ in newborns with low birth weight (with mortality in that group being 10-30\%) [29, 30]. Symptoms and signs of the disease usually occur after initiation of enteral nutrition in the first days of life in full-term neonates and in the first weeks of life in preterm babies [29]. At present, the modified Bell scale is used to assess the severity of NEC, but markers enabling quick detection and monitoring of intestinal damage are sought, one of them being FC [3, 29, 31-35]. Pergialiotis et al. [31] demonstrated, based on a systematic review (13 studies, 601 neonates) that FC is elevated in newborns with NEC. In the study of Thuijls et al. [35], the cut-off level at $286.2 \mathrm{ug} / \mathrm{g}$ stool, with a sensitivity of 0.86 and specificity of 0.93 (196), was obtained. Although the concentration of FC in neonates can be affected by the collection mode (even a $30 \%$ increase in the concentration of protein due to water absorption into the diaper) and lack of universally accepted reference values, ESPGHAN recommends using serial FC measurements as a noninvasive screening tool to alert the risk of developing NEC and monitor its course [3]; however, no cut-off values were obtained.

\section{Coeliac disease}

Coeliac disease is an autoimmune enteropathy caused by gluten hypersensitivity, which occurs in genetically predisposed individuals. The current diagnostic criteria were published by the ESPGHAN in 2020 [36]. With regard to histological assessment of intestinal biopsy, the presence of chronic inflammation with substantial intra-epithelial lymphocytes (IELs) infiltration is one of the main features of coeliac disease microscopy. The question of whether this chronic inflammation is expressed by a significant FC increase in individuals with coeliac disease while on a gluten-containing diet remains unclear. Only a few studies have assessed FC concentrations in patients with coeliac disease. Montalto et al. [37] did not demonstrate significant differences in protein concentrations in adult patients with coeliac disease and healthy individuals. Furthermore, no correlation was observed between FC levels and the severity of clinical symptoms and signs, as well as histopathological markers of mucosal damage.

Eretkin et al. [38] reported that FC value in patients with complete villous atrophy was significantly higher than in those with partial atrophy $(13.8 \pm 9.3 \mathrm{mg} / \mathrm{l} \mathrm{vs.} 3.7$ $\pm 1.8 \mathrm{mg} / \mathrm{l} ; p=0.005$ ). Balametkin et al. [39] showed significantly increased FC concentrations in children with newly diagnosed coeliac disease as compared with patients following a gluten-free diet and healthy individuals $(117.2 \mu \mathrm{g} / \mathrm{g}$; range [3.2-306 $\mu \mathrm{g} / \mathrm{g}$ ] vs. $3.7 \mu \mathrm{g} / \mathrm{g}$; range $[0.5-58.2 \mu \mathrm{g} / \mathrm{g}]$ vs. $9.6 \mu \mathrm{g} / \mathrm{g}$; range $[1-70 \mu \mathrm{g} / \mathrm{g}]$, respectively). FC concentrations were higher in patients presenting with GI manifestations than in asymptomatic individuals (142.8 $\mu \mathrm{g} / \mathrm{g}$ [12.2-306 $\mu \mathrm{g} / \mathrm{g}] \mathrm{vs} .79 .7 \mu \mathrm{g} / \mathrm{g}$ [3.2-243.2 $\mu \mathrm{g} / \mathrm{g}])$. However, no correlation was observed between FC concentrations and the degree of mucosal damage (according to the Marsh scale). A decrease in FC concentration after the introduction of a gluten-free diet was observed [40].

ESPGHAN experts underline the high individual variability of FC concentration range in patients with coeliac disease and do not recommend its use for the diagnosis and monitoring of coeliac disease [3].

Despite the lack of recommendations, elevated FC should raise attention to the possibility of an organic disease, including coeliac disease, in patients demonstrating GI signs and symptoms.

\section{Food allergy and food protein-induced enterocolitis syndrome}

Allergic reactions may be triggered by various foods, involve different immunological mechanisms (Ig-E-mediated, non-IgE-mediated, and mixed pattern), and present as GI and extraintestinal signs and symptoms. The highest frequency of food allergies is reported in infants and young children, with cow milk proteins being the most common allergens among this group $[41,42]$. The diagnostic gold standard remains the oral food challenge (OFC) which confirms the link between particular allergens and symptoms; however, it is difficult and time consuming. The question of whether FC could serve as a marker indicating the presence of GI inflammation in children with food allergy and supporting the diagnostic process was the subject of several studies. Merras-Salmio et al. [43] assessed FC concentrations at two time points (at baseline and on an elimination diet) in neonates and infants with IgE-mediated $(n=24)$ and non-IgE-mediated $(n=8)$ cow milk allergy. The control group comprised healthy individuals $(n=39)$. FC concentration was 
significantly higher only in children with non-IgE-mediated allergies and controls. After introducing a milkfree diet, FC concentrations were reassessed with decreased protein concentrations observed in patients with both types of food allergy (IgE-mediated $392 \pm 209$ vs. $218 \pm 90 \mu \mathrm{g} / \mathrm{g}, p=0.001$ and non- $\operatorname{IgE}$ mediated 889 \pm 278 vs. $359 \pm 288 \mu \mathrm{g} / \mathrm{g}, p=0.025)$ [43].

Belizón et al. [44] conducted a similarly designed study assessing FC at three time points (at baseline, one month, and three months following the introduction of the extensively hydrolysed protein-based formula) in 40 children with non-IgE-mediated cow milk allergy $(n=40)$ and in the control group $(n=30)$. The mean baseline FC concentration in the study group was significantly higher than in the control group $(442.65 \mu \mathrm{g} / \mathrm{g}$ vs. $100.30 \mu \mathrm{g} / \mathrm{g} ; p<0.001)$ and progressively declined over time in response to dietary intervention (FC values of $441 \mu \mathrm{g} / \mathrm{g}$ at diagnosis vs. $228 \mu \mathrm{g} / \mathrm{g}$ at one month, and $92 \mu \mathrm{g} / \mathrm{g}$ at three months of elimination diet introduction; $p<0001)$. FC concentration below $138 \mu \mathrm{g} / \mathrm{g}$ was proposed by the authors as a cut-off value excluding non-IgE-mediated cow milk protein allergy.

Food allergy and food protein-induced enterocolitis syndrome (FPIES) is a rare manifestation of food allergy that presents with vomiting, diarrhoea, lethargy, dehydration, hypotension, and hypothermia occurring within 1-4 hours of exposure to an allergen, with no skin or respiratory symptoms. In contrast to the general rules of food allergy diagnostic work-up, recognition of FPIES is based on detailed history taking and confirmed by resolution of symptoms after eliminating the trigger, without the need to perform OFC in most cases [45]. The usefulness of FC to support FPIES diagnosis has been investigated in only a few studies with conflicting results $[5,43$, $44,46]$. At our centre, we have demonstrated that FC offered to support food challenge in young child with FPIES evoked by cow milk and locust gum [5]. At present, ESPGHAN does not recommend the use of FC as a diagnostic tool or as a prognostic marker of cow milk protein allergy in children [3].

\section{GASTROINTESTINAL TRACT INFECTIONS}

Faecal calprotectin concentrations increase in GI infections of both bacterial and viral aetiologies. Chen et al. [19] evaluated FC in 153 children with infectious diarrhoea, and FC concentrations were higher in patients with Salmonella (median, 765 [252-1246] $\mu \mathrm{g} / \mathrm{g}$ ) or Campylobacter infections (median, 689 [307-1046] $\mu \mathrm{g} / \mathrm{g}$ ) than in patients infected with rotaviruses $(89[11-426] \mu \mathrm{g} / \mathrm{g}$ ), noroviruses $(93[25-405] \mu \mathrm{g} / \mathrm{g}$ ), or adenoviruses (95 [65$224] \mu \mathrm{g} / \mathrm{g}$ ). Higher FC values were found in patients with a more severe presentation (median, $843 \mathrm{vs.} 87 \mu \mathrm{g} / \mathrm{g}$ in patients with a mild disease course). The time after which the protein concentration normalised was not indicated in the study. In contrast, Czub et al. [47] evaluated FC in
50 children with infectious diarrhoea ( 29 of which were caused by rotavirus and 21 by Salmonella enteritidis) and 32 healthy subjects and did not demonstrate significant differences in FC performance.

ESPGHAN recommends not using FC in acute gastroenteritis to distinguish bacterial from viral infections [3].

\section{Cystic fibrosis}

Cystic fibrosis (CF) is a genetic disease caused by a mutation in the CFTR protein-encoding gene, with an incidence of $1: 5000$ in Poland. Secretory epithelial dysfunction and production of excessively thick mucus lead to bronchitis and pneumonia, exocrine pancreatic insufficiency, liver cirrhosis, and infertility in males [48]. Gastrointestinal tract manifestations of $\mathrm{CF}$ are related to mucous inspissation and dysmotility, including meconium ileus (MI), constipation, distal intestinal obstruction syndrome (DIOS), gastroesophageal reflux disease (GERD), and small bowel bacterial overgrowth $[49,50]$. FC concentrations in children with CF do not correlate with damage to the pancreas, liver, or cholestasis. However, the protein level in CF faeces was significantly higher than that in healthy individuals, indicating intestinal inflammation [51]; this may be caused by disturbances in the composition of intestinal microbiota [52].

Based on ESPGHAN [3], FC may be considered a marker of intestinal inflammation in CF, but there is not enough evidence of a correlation between FC level and enteropathy. More studies are required to verify the status of FC in patients with pancreatic sufficiency and age-related values, as well as the contribution of confounding factors such as lung calprotectin on FC levels. Caution is recommended when interpreting individual $\mathrm{FC}$ values as a marker of enteropathy in $\mathrm{CF}$.

\section{FUNCTIONAL GASTROINTESTINAL DISORDERS}

Functional GI disorders (FGIDs) include a combination of chronic and/or recurring manifestations, the presence of which may not be explained by an organic cause, that is, structural or biochemical, metabolic, inflammatory, and cancerous abnormalities detected in investigations [53].

Research suggests that FC is a useful and easy marker for differentiating between organic and functional disorders with $83 \%$ sensitivity and $84 \%$ specificity (IBD vs. IBS). A study in Norway described significant differences in FC levels between children with functional abdominal pain and children with IBD [54]. The Rome committee tool kit, an online resource for the diagnosis and management of FGIDs, currently recommends the use of FC to differentiate FGIDs from organic disorders in cases of unclear differential diagnoses. The recent ESPGHAN guidelines recommend addressing its usefulness in infant colic, functional abdominal pain, and functional constipation [3]. ESPGHAN recommends the use of FC to dif- 
ferentiate functional abdominal disorders from organic diseases. However, they do not recommend measuring FC in children with infantile colic and constipation due to inconsistencies in the available data [3].

\section{COVID-19}

Currently diarrhoea is recognized as a common extrapulmonary manifestation of COVID-19 infection both in adults (in 10\% subjects) and children as well (in 8.1\% subjects based on systematic review encompassing 1124 children by Souza et al.) $[55,56]$.

To check whether COVID-19 infection evokes GI inflammation the Italian group, Gemelli against COVID19, measured the FC concentration in 65 consecutive patients with positive swab test for SARS-CoV-2, and compared the results obtained in symptomatic subjects with radiological evidence of interstitial pneumonia and in a group without symptoms or evidence of pneumonia [57]. Faecal calprotectin was elevated in $29,2 \%$ cases with significantly higher frequency in patients with pathologic chest X-ray/CT scan (57.9\%). In turn, in group with normal FC level pathologic chest X-ray/CT scan occurred only in $10,9 \%$. The median FC value was $71.3 \mu \mathrm{g} / \mathrm{g}$ [Interquartile range, 18.8-248.0] [57]. The study demonstrated the GI involvement in the course of COVID-19. Results of a small pilot study proved that patients with COVID-19 and diarrhoea demonstrated a higher concentration of FC $(123.2 \pm 58.8 \mu \mathrm{g} / \mathrm{g})$ than those with COVID-19 without GI symptoms (FC $<50 \mu \mathrm{g} / \mathrm{g}$ ) [58].

The role of home-based FC monitoring in children with IBD during the pandemic restrictions was highlighted, whereas no data were published concerning FC usefulness in clinical work-up of non-IBD children presenting with SARS-CoV-2 associated GI symptoms $[59,60]$.

\section{OTHER DISEASES}

Faecal calprotectin concentration was also measured in other diseases such as appendicitis and Helicobacter pylori infection; however, ESPGHAN does not recommend the use of this test as a prognostic marker [3].

\section{SUMMARY}

Calprotectin is a marker of intestinal inflammation and neutrophil infiltration. It is helpful in differentiating between functional and organic disorders and monitoring patients with inflammatory bowel diseases, but will not replace colonoscopy. Different cut-off values are applied in children depending on the patient's age; hence, variability of the parameter for a given patient should be analysed.

\section{DISCLOSURE}

The authors declare no conflict of interest.

\section{REFERENCES}

1. Střiž I, Trebichavský I. Calprotectin - a pleiotropic molecule in acute and chronic inflammation. Physiol Res 2004; 53: 245-253.

2. Montalto M, Gallo A, Santoro L, et al. Role of fecal calprotectin in gastrointestinal disorders. Eur Rev Med Pharmacol Sci 2013; 17: 1569-1582.

3. Ribes Koninckx C, Donat E, Benninga M, et al. The Use of Fecal Calprotectin Testing in Paediatric Disorders: A Position Paper of the European Society for Paediatric Gastroenterology and $\mathrm{Nu}$ trition Gastroenterology Committee. J Pediatr Gastroenterol Nutr 2021; 72: 617-640.

4. Olender K, Bergmann K, Odrowąż-Sypniewska G. Kalprotektyna w kale jako marker zapalny w nieswoistych zapaleniach jelit. J Lab Diagn 2012; 48: 433-439.

5. Jędrzejczyk M, Bartnik K, Funkowicz M, Toporowska-Kowalska E. Locust bean gum induced FPIES in infant. J Investig Allergol Clin Immunol 2020; 30: 197-199.

6. Gisbert JP, McNicholl AG. Questions and answers on the role of faecal calprotectin as a biological marker in inflammatory bowel disease. Dig Liver Dis 2009; 41: 56-66.

7. Li F, Ma J, Geng S, et al. Fecal Calprotectin Concentrations in Healthy Children Aged 1-18 Months. PLoS One 2015; 10: e0119574.

8. Oord T, Hornung N. Fecal calprotectin in healthy children. Scand J Clin Lab Invest 2014; 74: 254-258.

9. Olafsdottir E, Aksnes L, Fluge G, Berstad A. Faecal calprotectin levels in infants with infantile colic, healthy infants, children with inflammatory bowel disease, children with recurrent abdominal pain and healthy children. Acta Paediatr 2002; 91: 45-50.

10. Hestvik E, Tumwine JK, Tylleskar T, et al. Faecal calprotectin concentrations in apparently healthy children aged 0-12 years in urban Kampala, Uganda: a community-based survey. BMC Pediatr 2011; 11: 9.

11. Berni Canani R, Rapacciuolo L, Romano MT, et al. Diagnostic value of faecal calprotectin in paediatric gastroenterology clinical practice. Dig Liver Dis 2004; 36: 467-470.

12. Ezri J, Nydegger A. Pediatrics. Fecal calprotectin in children: use and interpretation. Rev Med Suisse 2011; 7: 69-70.

13. Acevedoa D, Salvadora M, Girbesa J, Estana N. Fecal Calprotectin: A Comparison of Two Commercial Enzymoimmunoassays and Study of Fecal Extract Stability at Room Temperature. J Clin Med Res 2018; 10: 396-404.

14. Naess-Andresen CF, Egelandsdal B, Fagerhol MK. Calcium binding and concomitant changes in the structure and heat stability of calprotectin (L1 protein). Clin Mol Pathol 1995; 48: M278-M284.

15. Piekkala M, Alfthan H, Merras-Salmio L, et al. Fecal calprotectin test performed at home - a prospective study of pediatric patients with inflammatory bowel disease. J Pediatr Gastroenterol Nutr 2018; 66: 926-931.

16. Heida A, Knol M, Kobold AM, et al. Agreement Between HomeBased Measurement of Stool Calprotectin and ELISA Results for Monitoring Inflammatory Bowel Disease Activity. Clin Gastroenterol Hepatol 2017; 15: 1742-1749.

17. Haisma SM, Galaurchi A, Almahwzi S, et al. Head-to-head comparison of three stool calprotectin tests for home use. PLoS One 2019; 14: e0214751.

18. Sridhar M, Kesavelu D. Fecal calprotectin as a screening marker for inflammatory bowel disease. Indian Pediatr 2019; 56: 249-250.

19. Chen CC, Huang JL, Chang CJ, Kong MS. Fecal calprotectin as a correlative marker in clinical severity of infectious diarrhea and usefulness in evaluating bacterial or viral pathogens in children. J Pediatr Gastroenterol Nutr 2012; 55: 541-547.

20. Yang Z, Clark N, Park KT. Effectiveness and cost-effectiveness of measuring fecal calprotectin in diagnosis of inflammatory bowel 
disease in adults and children. Clin Gastroenterol Hepatol 2014; 12: 253.e2-62.e2.

21. Kolho K, Raivio T, Lindahl H, et al. Fecal calprotectin remains high during glucocorticoid therapy in children with inflammatory bowel disease. Scand J Gastroenterol 2006; 41: 720-725.

22. Bunn SK, Bisset WM, Main MJ, et al. Fecal calprotectin as a measure of disease activity in childhood inflammatory bowel disease. J Pediatr Gastroenterol Nutr 2001; 32: 171-177.

23. Bunn SK, Bisset WM, Main MJ, et al. Fecal calprotectin: validation as a noninvasive measure of bowel inflammation in childhood inflammatory bowel disease. J Pediatr Gastroenterol Nutr 2001; 33: 14-22.

24. Jusué V, Chaparro M, Gisbert JP. Accuracy of fecal calprotectin for the prediction of endoscopic activity in patients with inflammatory bowel disease. Dig Liver Dis 2018; 50: 353-359.

25. Henderson P, Anderson NH, Wilson DC. The diagnostic accuracy of fecal calprotectin during the investigation of suspected pediatric inflammatory bowel disease: a systematic review and meta-analysis. Am J Gastroenterol 2014; 109: 637.

26. Kostas A, Siakavellas SI, Kosmidis C, et al. Fecal calprotectin measurement is a marker of shortterm clinical outcome and presence of mucosal healing in patients with inflammatory bowel disease. World J Gastroenterol 2017; 23: 7387-7396.

27. Walkiewicz D, Werlin SL, Fish D, et al. Fecal calprotectin is useful in predicting disease relapse in pediatric inflammatory bowel disease. Inflamm Bowel Dis 2008; 14: 669-673.

28. van Rheenen PF. Role of fecal calprotectin testing to predict relapse in teenagers with inflammatory bowel disease who report full disease control. Inflamm Bowel Dis 2012; 18: 2018-2025.

29. Szczapa J. Martwicze zapalenie jelit. In: Standardy opieki medycznej nad noworodkiem w Polsce. Zalecenia Polskiego Towarzystwa Neonatologicznego. Wyd. Media-Press, Warszawa 2017; 233-239.

30. Fitzgibbons SC, Ching Y, Yu D, et al. Mortality of necrotizing enterocolitis expressed by birth weight categories. J Pediatr Surg 2009; 44: 1072-1075.

31. Pergialiotis V, Konstantopoulos P, Karampetsou N, et al. Calprotectin levels in necrotizing enterocolitis: a systematic review of the literaturę. Inflamm Res 2016; 65: 847-852.

32. Shenoy MT, Shenoy KT, Roseth A, et al. Diagnostic utility of fecal calprotectin as a biomarker of gut inflammation in neonates to predict necrotizing enterocolitis: a prospective study. Indian J Child Health 2014; 1: 99-104.

33. Bin-Nun A, Booms C, Sabag N, et al. Rapid fecal calprotectin (FC) analysis: point of care testing for diagnosing early necrotizing enterocolitis. Am J Perinatol 2015; 32: 337-342.

34. Terrin G, Passariello A, De Curtis M, et al. S100 A8/A9 protein as a marker for early diagnosis of necrotising enterocolitis in neonates. Arch Dis Child 2012; 97: 1102.

35. Thuijls G, Derikx JP, van Wijck K, et al. Non-invasive markers for early diagnosis and determination of the severity of necrotizing enterocolitis. Ann Surg 2010; 251: 1174-1180.

36. Husby S, Koletzko S, Korponay-Szabó I, et al. European Society Paediatric Gastroenterology, Hepatology and Nutrition Guidelines for Diagnosing Coeliac Disease 2020. J Pediatr Gastroenterol Nutr 2020; 70: 141-156.

37. Montalto M, Santoro L, Curigliano V, et al. Fecal calprotectin concentrations in untreated coeliac patients. Scand J Gastroenterol 2007; 42: 957-961.

38. Ertekin V, Selimoğlu MA, Turgut A, Bakan N. Fecal calprotectin concentration in celiac disease. J Clin Gastroenterol 2010; 44: 544-546.

39. Balamtekın N, Baysoy G, Uslu N, et al. Fecal calprotectin concentration is increased in children with celiac disease: relation with histopathological findings. Turk J Gastroenterol 2012; 23: 503-508.

40. Biskou O, Gardner-Medwin J, Mackinder M, et al. Faecal calprotectin in treated and untreated children with coeliac disease and juvenile idiopathic arthritis. J Pediatr Gastroenterol Nutr 2016; 63: e112-e115.

41. Sicherer SH. Epidemiology of food allergy. J Allergy Clin Immunol 2011; 127: 594-602.

42. Rona RJ, Keil T, Summers C, et al. The prevalence of food allergy: a meta-analysis. J Allergy Clin Immunol 2007; 120: 638-646.

43. Merras-Salmio L, Kolho KL, Pelkonen AS, et al. Markers of gut mucosal inflammation and cow's milk specific immunoglobulins in non-IgE cow's milk allergy. Clin Transl Allergy 2014; 4: 8.

44. Trillo Belizón C, Ortega Páez E, Medina Claros AF, et al. Faecal calprotectin as an aid to the diagnosis of non-IgE mediated cow's milk protein allergy. An Pediatr (Barc) 2016; 84: 318-323.

45. Nowak-Węgrzyn A, Chehade M, Groeth ME, et al. International consensus guidelines for the diagnosis and management of food protein-induced enterocolitis syndrome: Executive summaryWorkgroup Report of the Adverse Reactions to Foods Committee, American Academy of Allergy, Asthma \& Immunology. J Allergy Clin Immunol 2017; 139: 1111-1126.

46. Vila Sexto L. Latest Insights on Food Protein-Induced Enterocolitis Syndrome: An Emerging Medical Condition. J Investig Allergol Clin Immunol 2018; 28: 13-23.

47. Czub E, Nowak J, Moczko J, et al. Comparison of fecal pyruvate kinase isoform M2 and calprotectin in acute diarrhea in hospitalized children. Sci Rep 2014; 4: 4769.

48. Walkowiak J, Lisowska A. Mukowiscydoza. In: Socha P, Lebensztejn D, Kamińska D. Gastroenterologia Dziecięca. Podręcznik do specjalizacji. Wyd. Media-Press, Warszawa 2016; 382-386.

49. Colombo C, Ellemunter H, Houwen R, et al.; ECFS. Guidelines for the diagnosis and management of distal intestinal obstruction syndrome in cystic fibrosis patients. J Cyst Fibros 2011; 10 (suppl 2): S24-S28.

50. Werlin SL, Benuri-Silbiger I, Kerem E, et al. Evidence of intestinal inflammation in patients with cystic fibrosis. J Pediatr Gastroenterol Nutr 2010; 51: 304-308.

51. Więcek S, Woś H, Kordys-Darmolińska B, et al. The concentration of calprotectin in the stools of children with diagnosed cystic fibrosis. Prz Gastroenterol 2017; 12: 38-43.

52. Enaud R, Hooks K, Barre A, et al. Intestinal Inflammation in Children with Cystic Fibrosis Is Associated with Crohn's-Like Microbiota Disturbances. J Clin Med 2019; 8: 645.

53. Rome IV Criteria. Available at: https://theromefoundation.org/ rome-iv/.

54. Llanos-Chea A, Saps M. Utility of Diagnostic Tests in Children With Functional Abdominal Pain Disorders. Gastroenterol Hepatol (N Y) 2019; 15: 414-422.

55. Maslennikov R, Poluektova E, Ivashkin V, et al. Diarrhoea in adults with coronavirus disease-beyond incidence and mortality: a systematic review and meta-analysis. Infect Dis (Lond) 2021; 53: 348-360.

56. Souza TH, Nadal JA, Nogueira RJN, et al. Clinical manifestations of children with COVID-19: A systematic review. Pediatr Pulmonol 2020; 55: 1892-1899.

57. Ojetti V, Saviano A, Covino M, et al.; GEMELLI AGAINST COVID-19 group. COVID-19 and intestinal inflammation: Role of fecal calprotectin. Dig Liver Dis 2020; 52: 1231-1233.

58. Effenberger M, Grabherr F, Mayr L, et al. Faecal calprotectin indicates intestinal inflammation in COVID-19. Gut 2020; 69: 1543-1544.

59. Kennedy NA, Hansen R, Younge L, et al. Organisational changes and challenges for inflammatory bowel disease services in the UK during the COVID-19 pandemic. Frontline Gastroenterol 2020; 11 : 343-350.

60. Jere M, Garrick V, Curtis L, et al. Point-of-care faecal calprotectin testing in patients with paediatric inflammatory bowel disease during the COVID-19 pandemic. BMJ Open Gastroenterol 2021; 8: e000631. 